\title{
Livestock as Insurance and Social Status: Evidence from Reindeer Herding in Norway
}

\author{
Anne Borge Johannesen • Anders Skonhoft
}

Accepted: 7 October 2010 / Published online: 2 November 2010

(C) The Author(s) 2010. This article is published with open access at Springerlink.com

\begin{abstract}
The theory of livestock as a buffer stock predicts that agropastoralists facing substantial risks will typically use liquid assets such as livestock for self-insurance to smooth consumption. This paper examines this hypothesis for reindeer herders in Norway where the herders, in contrast to pastoralists in, say, sub-Saharan Africa, face well-functioning credit markets. Using survey data including slaughter responses to a hypothetical meat price increase, we test whether keeping reindeer as insurance against risks affects the slaughter response. Furthermore, we examine whether status motives for keeping large herds affect the harvest response to a changing slaughter price. As a background to the empirical analysis, a stochastic bioeconomic model describing Saami reindeer herding is formulated.
\end{abstract}

Keywords Pastoralism · Social status · Uncertainty

\section{Introduction}

In many semiarid low productive areas, such as the Sahel zone in sub-Saharan Africa, livestock raising is the dominant form of agricultural production (e.g., Fafchamps 1998). This is also the case in many cold alpine areas in northern Europe and elsewhere (e.g., Austrheim et al. 2008). Because of low vegetation productivity and strong seasonable growth variation, the utilization of such areas often takes place through a system of nomadic pastoralism, whereby the livestock are moved to different locations to match spatial and seasonal vegetation growth variations (see, e.g., Binswanger and McIntire (1987) for studies of semiarid tropics; Chang and Toutellotte (1993) for examples from the Balkans and southern Europe; and Johannesen and Skonhoft (2009) and the references therein for evidence from Scandinavia). Hence, migration of livestock and people in such environments may be

\footnotetext{
A. B. Johannesen · A. Skonhoft $(\varangle)$

Department of Economics, Norwegian University of Science and Technology, 7491 Trondheim, Norway e-mail: Anders.skonhoft@svt.ntnu.no
}

\footnotetext{
A. B. Johannesen

e-mail: anneborge@svt.ntnu.no
} 
seen as a direct response to vegetation shortages. Furthermore, because pastoralists in such settings are subject to frequent environmental shocks, migration may also provide an effective insurance mechanism against spatial vegetation shortages. Nomadic behavior is, however, not the only way of coping with such risk. As possible vegetation scarcity involves the prospect of a sudden dramatic decrease in livestock holdings, pastoralists may also manage risk through livestock accumulation, especially where credit and insurance markets are weak or even nonexistent (e.g., Doran et al. 1979; Binswanger and McIntire 1987; Perrings 1994; Fafchamps 1998; McPeak 2004).

The size of the livestock herd may therefore be an important insurance asset. In many nomadic societies, as well as in pastoral and agropastoral communities with less mobile herds, herd size can also provide other important nonmarket benefits. For example, in traditional pastoral societies herd size is often of importance for cultural reasons, as well as being an asset signaling social status (Walker 1993; Perrings 1994; Dasgupta and Mäler 1995; Fafchamps 1998; Fraser and Chisholm 2000). The benefit pastoralists derive from such nonmarket or nonconsumptive values may clearly lower the marginal utility of the livestock offtake relative to livestock inventory, and hence result in larger herds and higher grazing pressure compared with situations when such nonmarket values are absent (e.g., Perrings and Walker 1995). Furthermore, in the presence of nonmarket benefits, a higher meat price may lead to lower harvest and hence increased rather than reduced grazing pressure. This was demonstrated by Skonhoft and Johannesen (2000), who modeled the role of nonmarket benefits related to Saami reindeer herding in Norway and found a possible negative relationship between livestock slaughter and meat price. They considered herders as maximizing a weighted average of slaughter profit and herd size while at the same time facing an income constraint. In the case of a binding income constraint, a price increase allows the herders to slaughter fewer animals and still obtain the same slaughtering income. In this way, an increased meat price may stimulate herders to reduce the number of slaughtered animals. This was also hypothesized by Doran et al. (1979), who found a negative relationship between livestock slaughter and meat price in Swaziland. Bostedt (2005) demonstrated a similar result for Saami reindeer herding in Sweden.

Negative supply responses to a price increase can, however, also simply result from slow biological reproduction in the livestock dynamics. Jarvis (1974) presented evidence from beef cattle production in Argentina and found that a higher beef price may motivate the farmers to delay the timing of the slaughtering temporarily to achieve weight increase, inducing a negative short-run supply response. Eventually, as the biomass increases, allowing for higher meat offtake in the long run, the slaughter price response becomes positive. That is, following this logic, farmers respond to a permanent price increase by keeping animals away from the market in the short run to increase the animals' weight gain for future slaughtering. On the other hand, when facing a temporary price increase, herders may choose to increase the slaughter supply in the short run, and subsequently reduce future supplies to correct for the stock shortfall (Rosen 1987).

Nonmarket benefits still seem to be important in many economies based on nomadic pastoralism. Even in the presence of well-functioning capital markets, Skonhoft (1999); Skonhoft and Johannesen (2000), and Riseth and Vatn (2009) argued that the insurance and status motives are important determinants of herd size in Saami societies practicing nomadic pastoral reindeer herding in Norway. See also Sect. 3 below. Bostedt (2005) argued that cultural values, such as the intrinsic value of being active in reindeer herding, motivate the Saamis to keep large herds in Sweden. Using cross-sectional survey data, he regressed the slaughter response to a changing meat price on herd size and demonstrated that large herds (presumably caused by cultural nonmarket values) imply a negative slaughter 
response. However, here no attempt was made to explicitly control for nonmarket livestock benefits.

The present paper presents evidence on herders' perceptions of nonmarket values using survey data from Saami reindeer herding in northernmost Norway (Finnmark county). A large proportion of the herders emphasize that the size of the reindeer herd is important to provide insurance against unfavorable environmental conditions, and social status within the herding community. A stochastic bioeconomic model is formulated to analyze how such values may affect herders' behavior in the presence of environmental shocks and changing economic conditions. The model is formulated in Sect. 2, where the price effects on harvest and stock size are studied. The analysis extends the existing literature (e.g., Fafchamps 1998) in making the working of the herd-size effect clearer. Links to some testable empirical hypotheses are also provided. The paper proceeds by presenting descriptive data from the survey area in Sect. 3, while the empirical analysis of how slaughtering responds to a changing meat price is found in Sect. 4. Section 5 summarizes our main findings.

\section{A Model of Reindeer as a Source of Insurance and Social Status}

In what follows, a model of an individual livestock herder facing environmental shocks is formulated, where stock size as a measure of social status, as well as a possible insurance motive, is included. It is assumed that each herder at time $t$ derives utility from the social status gained by keeping a large number of animals, $y_{t}$, relative to the average herd size $\bar{y}_{t}$ in the community. Notice that this stock effect may also be readily interpreted as an insurance motive (see, e.g., Fafchamps 1998). We assume the herding community is 'large' in the sense that the individual effect on average stock size is negligible (see also Brekke and Howarth 2002). We also assume that all animals slaughtered, $h_{t}$, are sold at a fixed and certain price, $P$, and that meat production is the only (endogenous) source of income ${ }^{1}$. We further assume that slaughter costs are stock independent, so that $P$ may be interpreted as a 'net' price, and neglecting any costs related to livestock maintenance, the current herding profit reads $\pi_{t}=P h_{t}$. The individual herder is assumed to maximize expected present value utility over slaughter income and relative herd size, given as:

$$
\mathrm{EPV}=E_{0} \sum_{t=0}^{\infty} \frac{1}{(1+\delta)^{t}}\left[U\left(\pi_{t}\right)+W\left(y_{t} / \bar{y}_{t}\right)\right]
$$

Utility is strictly increasing in income, $U^{\prime}>0$, and herders are assumed to be risk averse, i.e., $U^{\prime \prime}<0$. Furthermore, utility is strictly increasing in social status, $W^{\prime}>0$, but at a decreasing rate, i.e., $W^{\prime \prime}<0$. $E_{0}$ is the expectation operator, where the expectation is formed at the very beginning of the planning horizon, $t=0$, and $\delta$ is the discount rate.

The individual livestock herd grows according to:

$$
y_{t+1}=z_{t}\left[y_{t}+F\left(y_{t}\right)-h_{t}\right],
$$

where $F\left(y_{t}\right)$ represents natural growth, assumed to be density dependent and described by a one-peaked concave function. We think of this as a standard logistic function. In the present

\footnotetext{
1 The meat price is hence assumed to be exogenous to the individual reindeer management unit. This assumption seems reasonable in terms of the market size and existing regulations: Meat production in West Finnmark equals 28 per cent of the total reindeer meat production in Norway (NRHA 2007) and The General Agreement between the reindeer herder organization removed the target price in 2002/2003 to allow for the reindeer meat price to adjust according to changing market conditions (St. prp. nr. 76 (2008-2009)).
} 
exposition, any effect from herd size on vegetation quantity is neglected, meaning that we are ignoring any possible ecological interactions caused by herd size. Therefore, the individual herd size growth depends only on own stock size. $z_{t}$ is a stochastic variable reflecting shifting environmental conditions, i.e., climatic variations affecting vegetation growth, fluctuations in snow cover, changing predation pressure from carnivores, and so forth. Environmental shocks are assumed to be independent and identically distributed (i.i.d.) over time with unit mean, $E\left[z_{t}\right]=1$, and finite support, $0<z_{\text {low }}<z_{t}<z_{\text {high }}<\infty$. Note that the above formulation implies that harvest at time $t$ is based on the actual stock, while the surplus stock is prudent for shifting environmental conditions. Therefore, the stock in year $(t+1)$, after slaughtering and natural growth, is uncertain. This is the same setup as in the seminal Reed (1979) 'escapement fishery' paper.

When current and future slaughter levels are chosen so as to maximize present value expected utility, the value function is defined as $V_{t}\left(y_{t}\right)=\max _{h_{t}}^{\max }\left\{E_{t} \sum_{s=t}^{\infty}\left[U\left(\pi_{s}\right)+W\left(y_{s} / \bar{y}_{s}\right)\right] /\right.$ $\left.(1+\delta)^{s-t}\right\}$. Because slaughtering and stock size are nonstochastic within the present period, the corresponding Bellman equation can be written as:

$$
V_{t}\left(y_{t}\right)=\max _{h_{t}}\left\{U\left(\pi_{t}\right)+W\left(y_{t} / \bar{y}_{t}\right)+\frac{1}{1+\delta} E_{t}\left[V_{t+1}\left(y_{t+1}\right)\right]\right\},
$$

where the animal growth Eq. (2) is the constraint. In addition, the initial size of the herd $y_{0}$ is known.

The first-order condition of this problem for an internal solution reads $U^{\prime}\left(\pi_{t}\right) P$ $+\frac{1}{1+\delta} E_{t}\left[V_{t+1}^{\prime}\left(y_{t+1}\right)\left(\partial y_{t+1} / \partial h_{t}\right)\right]=0$, or $U^{\prime}\left(\pi_{t}\right) P=\frac{1}{1+\delta} E_{t}\left[V_{t+1}^{\prime}\left(y_{t+1}\right) z_{t}\right]$ when taking the animal growth Eq. (2) into account. When using the envelope theorem and the animal growth equation, and evaluating this expression at $(t+1)$, we next find $V_{t+1}^{\prime}\left(y_{t+1}\right)=$ $W^{\prime}\left(y_{t+1} / \bar{y}_{t+1}\right)\left(1 / \bar{y}_{t+1}\right)+\left[1+F^{\prime}\left(y_{t+1}\right)\right] U^{\prime}\left(\pi_{t+1}\right) P$ (more details in the Appendix). Then, inserting into the first-order condition (3), this condition may be rewritten as:

$$
U^{\prime}\left(\pi_{t}\right) P=\frac{1}{1+\delta} E_{t}\left\{\left[W^{\prime}\left(y_{t+1} / \bar{y}_{t+1}\right)\left(1 / \bar{y}_{t+1}\right)+\left[1+F^{\prime}\left(y_{t+1}\right)\right] U^{\prime}\left(\pi_{t+1}\right) P\right] z_{t}\right\}
$$

Equation (4) states that optimal slaughtering at time $t$ is determined by the equality between the marginal utility of current slaughtering and next year's expected marginal utility of livestock savings, where the latter includes the marginal utility of social status, as well as other possible stock motives, and slaughtering. Condition (4) and the population growth Eq. (2) describe the solution of the present optimization problem through two interconnected firstorder difference equations in harvest $h_{t}$ and number of animals $y_{t}$. Given the initial stock value $y_{0}$, the optimal paths can in principle be calculated.

In the absence of the status effect, it is seen that price plays no role in the harvesting decision, as (4) then simply reduces to $U^{\prime}\left(\pi_{t}\right)=\frac{1}{1+\delta} E_{t}\left\{\left[1+F^{\prime}\left(y_{t+1}\right)\right] U^{\prime}\left(\pi_{t+1}\right) z_{t}\right\}$ when $P$, as here, is assumed to be known with certainty. This result is obvious, as the value of income no longer plays any role in the trade-off. What matters then is the size of the harvest only. In the absence of environmental uncertainty, i.e., $z_{t}$ is nonstochastic and hence equals one, this condition reduces further to $U^{\prime}\left(\pi_{t}\right)=\frac{1}{1+\delta}\left[1+F^{\prime}\left(y_{t+1}\right)\right] U^{\prime}\left(\pi_{t+1}\right)$. With, say, $F^{\prime}\left(y_{t+1}\right)>\delta$, we find $U^{\prime}\left(\pi_{t}\right) / U^{\prime}\left(\pi_{t+1}\right)>1$ and therefore $h_{t+1}>h_{t}$, i.e., the harvest increases over time. In the steady state, $h_{t+1}=h_{t}=h^{*}$, stock growth equals the discount rate, $F^{\prime}\left(y^{*}\right)=\delta$. This is a well-known result from standard bioeconomic theory when there are no stock-dependent 
harvesting costs (see, e.g., Clark 1990). However, whether this steady state is stable and reachable from $y_{0}$ depends on the parameterization of the model. ${ }^{2}$

With the status effect present, but still in the absence of environmental uncertainty, Eq. (4) reads $U^{\prime}\left(\pi_{t}\right) P=\frac{1}{1+\delta}\left[W^{\prime}\left(y_{t+1} / \bar{y}_{t+1}\right)\left(1 / \bar{y}_{t+1}\right)+\left[1+F^{\prime}\left(y_{t+1}\right)\right] U^{\prime}\left(\pi_{t+1}\right) P\right]$. This expression indicates that the social status motive, as well as the insurance motive, for livestock holding partially works in the direction of higher present marginal income utility, and hence a lower year $t$ slaughter level. Therefore, not surprisingly, we may expect herders with preferences for social status to keep more animals than other herders do. On the other hand, the stock-price effect, as well as the harvest-price effect, is ambiguous. The intuition here is that the dynamics may be complex, and may even include cycles (e.g., Fafchamps 1998) (cf. also footnote 2).

In the steady state with no uncertainty, we have $F^{\prime}\left(y^{*}\right)=\delta-\frac{W^{\prime}\left(y^{*} / \bar{y}\right)(1 / \bar{y})}{P U^{\prime}\left(P h^{*}\right)}$ together with $F\left(y^{*}\right)=h^{*}$ where the status effect is clear and evident. Now, also, the meat-price effect is unambiguous, and we find that a higher price increases the marginal utility of the harvest relative to the marginal utility of social status. Therefore, a higher slaughter price motivates herders to temporarily increase the offtake and leave a smaller stock for the future. That is, the direct effect of a higher slaughter price on the slaughter level, i.e., when ignoring indirect effects working through a changing stock level over time, is positive. The temporary slaughter response is, however, weaker for herders keeping large herds relative to the community average (see also the Appendix).

The permanent price effect on harvest is, however, generally ambiguous because the effect then depends on whether the steady state is located to the left- or right-hand side of $y^{m s y}$ ( $m s y=$ maximum sustainable yield). If the preference for social status or insurance is strong and the steady state is initially located to the right-hand side of $y^{m s y}$, a higher slaughter price will increase the steady state harvest, while a further price increase will reduce steady state slaughtering. These effects are simply the well-known upward-sloping supply curve from the fishery economics literature that occurs when the natural growth function, as here, is assumed to be of the density-dependent one-peaked type.

We now look more closely at how the presence of uncertainty in condition (4) may affect the above reasoning. Shifting environmental conditions through $z_{t}$ occur between periods. That is, after harvest year $t$ the left-hand side of (4) has a given value. Then, a negative environmental shock will ceteris paribus increase the expected future marginal utility of livestock (right-hand side of Eq. (4)), as the value of the left-hand side is fixed. Because this value is equated with the current and given marginal utility of slaughtering, the harvesting level in period $t$ falls (see also McPeak 2004). This implies that the risk of poor future environmental conditions stimulates herders to keep more animals than in the absence of risk (see also the Appendix).

The notion of a steady state has no obvious meaning when uncertainty is present. However, the expected steady state $E\left[y_{t+1}-y_{t}\right]=0$, or $E\left[y_{t+1}\right]=E\left[y_{t}\right]=\tilde{y}$, yields the herd size around which the long-term stock level will fluctuate. In the same manner, $E\left[h_{t+1}\right]=E\left[h_{t}\right]=\tilde{h}$ represents the expected steady state harvest. Inserted into condition (4), we find $U^{\prime}(P \tilde{h}) P=\frac{1}{1+\delta} E\left\{\left[W^{\prime}(\tilde{y} / \bar{y})(1 / \bar{y})+\left[1+F^{\prime}(\tilde{y})\right] U^{\prime}(P \tilde{h}) P\right] z_{t}\right\}$, or $U^{\prime}(P \tilde{h}) P=\frac{1}{1+\delta}\left[W^{\prime}(\tilde{y} / \bar{y})(1 / \bar{y})+\left[1+F^{\prime}(\tilde{y})\right] U^{\prime}(P \tilde{h}) P\right]$, which is exactly the same expression as without uncertainty. The expected steady state is therefore identical to the

2 This last proposition is in contrast to the standard bioeconomic model formulated in continuous time where the transitional dynamics are of the saddle path type with two stable arms leading to the steady state. 
steady state when environmental uncertainty is neglected, $\tilde{y}=y^{*}$, and the price effects on herd size and harvest are identical in these two cases.

Having conceptually analyzed the role of environmental uncertainty and nonmarket values, we now turn to analyzing whether insurance and social status motives for livestock keeping play a role in reindeer herding in northernmost Norway. In doing so, we distinguish between the two nonmarket values of reindeer, social status and insurance, and test whether they affect the temporary slaughter response due to changing meat price. However, before doing so, more detailed descriptions of reindeer herding and our data are given.

\section{Reindeer Herding in Northernmost Norway}

\subsection{The Reindeer Herding Area}

We analyze the slaughter response to a price change using cross-sectional survey data from interviews with Saami reindeer herders in western Finnmark in northern Norway conducted in July 2007. The reindeer herding region of western Finnmark covers a total area of some $24,000 \mathrm{~km}^{2}$ and includes 216 reindeer management units with an aggregated reindeer population of 94,000 animals (NRHA 2007). The survey covers 15 of the 25 reindeer herding districts in this region, and 44 reindeer management units. One management unit typically covers several reindeer owners, all of whom are usually relatives of the unit manager. The owners include both active and nonactive herders, but in order to restrict the sample to active herders only, the unit managers were interviewed. The average number of owners per unit in the survey sample is 6.2 persons, while the western Finnmark average is 6.1 (NRHA 2007).

The selected districts include both coastal and interior districts and, hence, reflect the geographical conditions of the western Finnmark herding area well. Prior to the survey, 60 management units were approached and asked to participate. This number is small compared with the number of management units in the whole area, but should be viewed in light of the time (because of large traveling distances) required to conduct such a survey. Some of the approached managers did not have the opportunity to participate, but whenever possible another manager from the respective district was included. The sample was, however, reduced to 44 units as the survey proceeded because some managers chose to withdraw from the survey by the time we arrived. The reasons were various; some were out in the fields herding their animals, or not reachable for other reasons, while others simply refused to participate.

The northernmost parts of Norway constitute the main area of reindeer herding in the country. Saami reindeer herding in this area can be traced to the hunting of wild reindeer since time immemorial. During the 15th century, entire reindeer herds were domesticated, and part of the Saami people became herding nomads. This tradition has been preserved until today (Johansen and Karlsen 2005). Reindeer follow a seasonal migration pattern across a huge area during the year due to food scarcity and shifting vegetation conditions (cf. also the introductory section). During the summer, reindeer graze on grass, herbs and sedges on the islands and peninsulas near the coast, while the winter ranges are found in the interior continental parts characterized by vegetation types rich in lichens (Johansen and Karlsen 2005) (see Fig. 1). The Reindeer Farming Act gives the Saamis in northern Norway the right to graze their herds in practically all nonprivate land areas in the county (Austenå and Sandvik 1998) to secure the migration between the coast and inland. This migration route has been important to secure an appropriate balance between winter and summer ranges (Johansen and Karlsen 2005). 


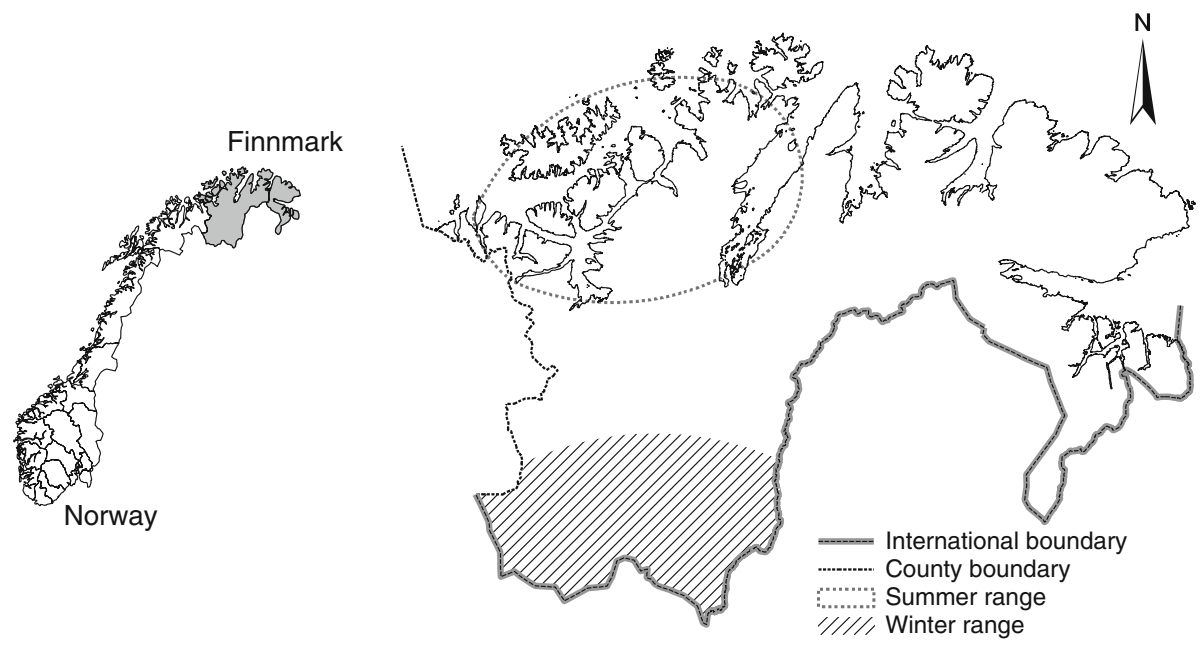

Fig. 1 Map of Finnmark reindeer herding area indicating the migration route in West Finnmark

On a national scale, reindeer herding in Norway is a small industry. The total industry comprises 556 management units keeping 240,000 reindeer in total (NRHA 2007). There is a restriction on entering the industry because only Saami people may herd reindeer (NRHA 2007), and a unit leader (i.e., the owner and manager of a management unit) must have herding as his main occupation (Austenå and Sandvik 1998). Even though this industry is small on a national scale, reindeer herding is of great importance to the Saami people, both economically and culturally. The Norwegian government, both in official statements (e.g., St. prp. nr. 1 (2007-2008)) and through different types of subsidies, has also emphasized that reindeer herding is of the greatest importance with regard to sustaining the Saami culture.

Saami reindeer herders rely on reindeer as their only source of agricultural production. Reindeer meat is the main product produced and sold on the market, but some herders supplement this with fur and handicrafts. A negative environmental shock (e.g., very packed snow cover) will therefore cause both an income and an asset shock due to reduced slaughter weight and livestock loss. Other negative shocks include loss to predators and traffic accidents. In contrast to most pastoral societies in developing countries, however, Saami reindeer herders are faced with a well-functioning credit market. Furthermore, herders are compensated by the government for reindeer losses caused by predators or traffic accidents to the full slaughter and grant value of the animal (Labba et al. 2006). ${ }^{3}$ Still, a number of herders perceive large herds as an insurance against adverse herding conditions. Having a large herd also seems to be crucial for the prestige and social status it confers (see below). A large herd reflects a successful and competent herder. It has been argued that the status motive has been replaced by an increased focus on productivity in the southern parts of Norway, whereas it is still intact in Finnmark (Riseth and Vatn 2009). Recalling the problem of overgrazing in Finnmark over the past decades (e.g., NRHA 2007), it is critically important to understand the objectives that influence the size of a reindeer herd when defining economic policies aimed at reducing the grazing pressure. First, such motives tend partially to result in larger herds and more intensive grazing pressure (cf. also the introductory section and Sect. 2). Second, a slaughter

3 Losses to traffic accidents involving cars are compensated by the insurance company of the motorist, while losses to accidents involving trains are compensated by the government (Labba et al. 2006). 
subsidy, which was intended to increase the offtake and reduce grazing pressure in northern Norway, may give unexpected results when motives of self-insurance and social status are present (cf. also introductory section).

The aim of the empirical part of this paper is to investigate to what extent the size of the reindeer herd is seen as a source of insurance and social status. This is described in Sect. 3.2 below. Furthermore, in Sect. 4 we test whether such motives for keeping large herds affect the temporary slaughter response to an increase in the slaughter price. The theoretical model above predicts a temporary positive slaughter response, but herders keeping large herds relative to the community average, with a preference for social status, tend to have a lower slaughter response than herders without such a preference. Rather than testing for the impact of environmental shocks, we investigate whether herders keeping large herds relative to the community average and, hence, perceiving a large herd as a source of insurance, have a lower slaughter response than others (for a further description, see Sect. 4 below).

\subsection{Descriptive Data}

Table 1 (left-hand side) shows the sample herd-size distribution according to the response alternatives described in the survey. About $23 \%$ of the management units have a flock size of between 301 and 400 animals. The average number of owners in management units keeping 301-400 animals is below that in units keeping more animals (see Table 2). Although the survey does not distinguish between active and nonactive owners, this result may well reflect that more labor (i.e., active owners) is required to manage larger herds. A relatively large proportion of the sample, just under 40\%, keeps 501-600 animals. This is not surprising, as production grants and slaughter subsidies are only available when the herd size does not exceed 600 animals (NRHA 2007). However, while $38 \%$ of the management units in Western Finnmark keeps 401-600 animals (right-hand side of Table 1), a larger proportion $(48 \%)$ reports the same in our sample. Hence, our sample is somewhat biased towards management units keeping large herds. Still, the sample average counts 401-500 animals, which corresponds well with the Western Finnmark average of 435 animals per management unit.

Table 1 Herd class distribution

\begin{tabular}{|c|c|c|c|c|c|c|}
\hline \multirow[t]{2}{*}{ Variable } & \multicolumn{3}{|l|}{ Survey sample } & \multicolumn{3}{|l|}{ Western Finnmark ${ }^{b}$} \\
\hline & Description & $\mathrm{N}$ & $(\%)$ & Description & $\mathrm{N}$ & $(\%)$ \\
\hline \multirow{8}{*}{$\begin{array}{l}\text { Herd class per } \\
\text { management unit }\end{array}$} & $0-100$ reindeer & 1 & 2.3 & 0-200 reindeer & 39 & 18.1 \\
\hline & $101-200$ reindeer & 2 & 4.5 & 201-400 reindeer & 68 & 31.5 \\
\hline & 201-300 reindeer & 1 & 2.3 & 401-600 reindeer & 82 & 38.0 \\
\hline & $301-400$ reindeer & 10 & 22.7 & $>600$ reindeer & 27 & 12.5 \\
\hline & $401-500$ reindeer & 4 & 9.1 & & & \\
\hline & $501-600$ reindeer & 17 & 38.6 & & & \\
\hline & $601-700$ reindeer & 2 & 4.5 & & & \\
\hline & $>700$ reindeer & 4 & 9.1 & & & \\
\hline Total & & $41^{\mathrm{a}}$ & & & 216 & \\
\hline
\end{tabular}

a Three observations are missing

b Data from NRHA (2007) 
Table 2 Number of owners and income per management unit according to herd class

\begin{tabular}{lcl}
\hline Herd class & Mean number of owners & Mean income $(1,000$ NOK) \\
\hline $0-100$ & 5.0 & $0-99$ \\
$101-200$ & 4.5 & $0-99$ \\
$201-300$ & 7.0 & $150-199$ \\
$301-400$ & 4.2 & $200-249$ \\
$401-500$ & 6.8 & $250-299$ \\
$501-600$ & 5.3 & $300-399$ \\
$601-700$ & 11.5 & $400-499$ \\
$>700$ & 14.0 & $300-399$ \\
\hline
\end{tabular}

Table 3 Responses to: "How important is it for you to be a reindeer herder?"

\begin{tabular}{llll}
\hline Response alternative & $\mathrm{N}$ & $(\%)$ & Mean herd class \\
\hline $\begin{array}{l}\text { 1. "I will quit as a reindeer herder if I get an } \\
\text { occupation that will provide the same } \\
\text { income" }\end{array}$ & 1 & 2.3 & $>700$ \\
$\begin{array}{l}\text { 2. "I will quit as a reindeer herder if I get an } \\
\text { occupation that will provide a better } \\
\text { income" }\end{array}$ & 5 & 11.4 & $301-400$ \\
$\begin{array}{l}\text { 3. "I will not quit as a reindeer herder" } \\
\text { 4. "I will not quit as a reindeer herder and it } \\
\text { is important to me that the next generation } \\
\text { takes over" }\end{array}$ & 7 & 15.9 & $401-500$ \\
Total & & 70.4 & $501-600$ \\
\hline
\end{tabular}

Table 4 Responses to assertions on non-use values

\begin{tabular}{lcclll}
\hline $\begin{array}{l}\text { "A large herd is } \\
\text { important... }\end{array}$ & $\mathrm{N}$ & Strongly disagree & Disagree & Agree & Strongly agree \\
\hline $\begin{array}{l}\text {. as an insurance } \\
\text { in times of } \\
\begin{array}{l}\text { adverse } \\
\text { conditions" }\end{array}\end{array}$ & 43 & $18.6 \%(401-500)$ & $30.3 \%(301-400)$ & $16.3 \%(501-600)$ & $34.8 \%(501-600)$ \\
$\begin{array}{l}\text {. to gain social } \\
\text { status" }\end{array}$ & 42 & $38.1 \%(401-500)$ & $35.7 \%(501-600)$ & $7.2 \%(601-700)$ & $19.0 \%(401-500)$ \\
\hline
\end{tabular}

Mean herd class in parenthesis

We asked management unit leaders a number of questions concerning the importance of being an active herder. First, about $70 \%$ of the sample agreed, or strongly agreed, that being an active herder is vital to sustain the Saami culture. Second, more than $85 \%$ of the sample seems reluctant to quit reindeer herding, even if given better income opportunities (see Table 3). This result indicates that herders earn some intrinsic utility from being an active herder, and fits well with the findings about reindeer herding in Sweden (again, see Bostedt 2005). Those who also emphasize the importance of future generations have, on average, larger flock sizes than others (except for the single respondent in answer alternative 1). This may indeed reflect that larger herds are perceived as crucial in order to secure the possibility that future generations can stay in reindeer herding. In contrast to Bostedt (2005)), the unit leaders were also specifically asked whether they perceived their animals as valuable 
Table 5 Responses to a $100 \%$ price increase

\begin{tabular}{lll}
\hline Response alternative & $\mathrm{N}$ & Mean herd class \\
\hline Reduce slaughter & $0(0.0 \%)$ & \\
No change in slaughter & $20(45.5 \%)$ & $401-500$ \\
Increase slaughter & $22(50.0 \%)$ & $501-600$ \\
Don't know & $2(4.5 \%)$ & $401-500$ \\
\hline
\end{tabular}

in other respects, as well as their slaughter value. They were presented with two different nonmarket values, insurance value and social status, and were asked to indicate whether, and to what degree, these were detrimental to herd size (see Table 4). Fifty-one percent of the sample agree, or strongly agree, that herd size is important in providing insurance against adverse herding conditions. The proportion perceiving herd size as important for social status is lower, but $26 \%$ agreed, or strongly agreed, with this assertion. Those management units who agree/strongly agree with the insurance motive keep, on average, more animals than the others. ${ }^{4}$ On the other hand, the herd size of respondents who agree/strongly agree with the status motive is not significantly different from others.

In order to analyze how herders respond to changes in the slaughter price, each herder was asked whether the number of animals slaughtered each year would change when faced with a hypothetical $100 \%$ increase in the per-kilo slaughter price (see Table 5). In contrast to the findings in Sweden (Bostedt 2005), none of the respondents in our survey would choose to reduce the slaughter. Therefore, there is no sign of any negative supply responses in this sample. Moreover, while just $8 \%$ of the Swedish reindeer herders report a positive supply response, $50 \%$ indicate such behavior in the present survey. Third, although not significantly different, herders with a positive supply response keep, on average, more animals than others in the present sample. The Swedish findings, on the other hand, predict the opposite relationship (see also Sect. 4 below).

\section{Empirical Specification and Estimation Results}

As already indicated, Saami reindeer herding is much more multifaceted than optimizing meat production only. The herding provides benefit to its owners through cultural identity, and a large herd size may gain social status within the Saami community (Tables 3 and 4). We now analyze how nonmarket values influence how herders respond to a hypothetical slaughter price increase, where our focus is on values related to insurance and social status. In contrast to the literature on livestock as a buffer stock (e.g., Fafchamps et al. 1998), actual livestock transactions and shocks are not included in our data set. Nonetheless, the data cover information on different nonmarket livestock values as perceived by the herders themselves. The data set is, therefore, in the present case well suited to separating the role of any insurance value from that of social status. Therefore, instead of investigating how actual environmental shocks affect slaughtering, we treat insurance motives as a nonmarket value of livestock, and test whether such preferences affect the slaughter response.

The response to a hypothetical $100 \%$ increase in the price per kilo of slaughtered meat (Table 5 above) is used to model the supply response. The logit specification of the empirical model is given as:

4 The null hypothesis of equal mean herd sizes across the groups is rejected at the $5 \%$ level of significance. 


$$
\partial h^{i} / \partial P=\left\{\begin{array}{ll}
1 & \text { if } \partial h^{i} / \partial P>0 \\
0 & \text { otherwise }
\end{array},\right.
$$

where $\partial h^{i} / \partial P=a+\boldsymbol{b} \boldsymbol{X}^{i}+u^{i}$, and $\boldsymbol{X}^{i}$ and $\boldsymbol{b}$ are vectors of explanatory variables and coefficients, respectively. $u^{i}$ is the error term and $i=1, \ldots, N^{5} . \partial h^{i} / \partial P=1$ if the herder $i$ chooses to increase the slaughter, while $\partial h^{i} / \partial P=0$ if the herder $i$ chooses to keep the slaughter level unchanged. The herders were presented with the following question: "Given the current size of your herd, how would you change your slaughter level if you were faced with a long-lasting doubling in the per-kilo meat price?" That is, they were confronted with a permanent price increase and asked to consider the herd size as exogenous when responding to the question. In light of our theoretical reasoning (Sect. 2 above), we hence test whether nonmarket values affect the temporary slaughter response. Different specifications of the supply response are presented in Table 6.

$H E R D$ measures the herd class average as a proxy for individual herd size. INSUR is a dummy variable with value one for herders who agree, or strongly agree, that herd size is important in providing insurance against adverse herding conditions, and zero otherwise. The dummy STATUS equals one for herders who agree, or strongly agree, that herd size is important for social status, otherwise zero. From the theoretical model, we expect herders with nonmarket values to temporarily be less likely to have a positive supply response compared with herders who impose lower nonmarket values on their herds. The latter two variables are also included in interaction terms with the herd size as INSUR*HERD and STATUS*HERD, respectively, to determine whether herders with nonmarket values are less likely to have a positive supply response if they actually keep large herds. $A G E$ reflects the age of the respondent, and is included to capture possible differences across generations. Summary statistics for these variables are reported in Appendix Table 7.

Table 6 reports the logit estimates. The coefficient of herd size HERD in regression (a) is positive, but only weakly significantly different from zero. However, when controlling for nonmarket values, as in models (b) and (d), the coefficient becomes positive and significant. This indicates that owners of large herds are more likely to increase slaughtering when confronted with a permanent price increase, in contrast to the negative relationship between herd size and supply response as demonstrated by Bostedt (2005) in Swedish reindeer herding. He presumed a positive relationship between herd size and nonmarket values, and interpreted the negative coefficient as a result of high nonmarket values. Instead, we control for the insurance motive for keeping a large herd in model (b). The coefficient of INSUR is positive, but only weakly significantly different from zero. However, the interaction term has a negative and significant impact on the supply response, indicating that owners of large herds who value the herd as insurance are less likely to increase their slaughter than owners with no insurance motive. In contrast, whether or not herders see herd size as important to gaining social status seems to have no significant impact on the supply response in models (c) and (d).

Models (e) and (f) provide a further analysis of the impact of social status on the slaughter response by controlling for relative herd size. These models include two distinct variables for relative herd size to reflect different patterns of interaction between herders across grazing seasons. During the summer grazing period, when the animals graze in the coastal areas (cf. Fig. 1 above), the pastures are divided into 25 well-defined grazing districts; that is, the herders only interact with other herders residing in the same district. The number of reindeer units in a summer district ranges from 1 to 20, with an average of 8.6 units (NRHA 2007). In the winter season, on the other hand, the animals graze on inland common pastures shared by a larger number of reindeer units (cf. also Fig. 1). To capture any status motive

${ }^{5}$ See Johnston and Dinardo (1997), chapter 13. 


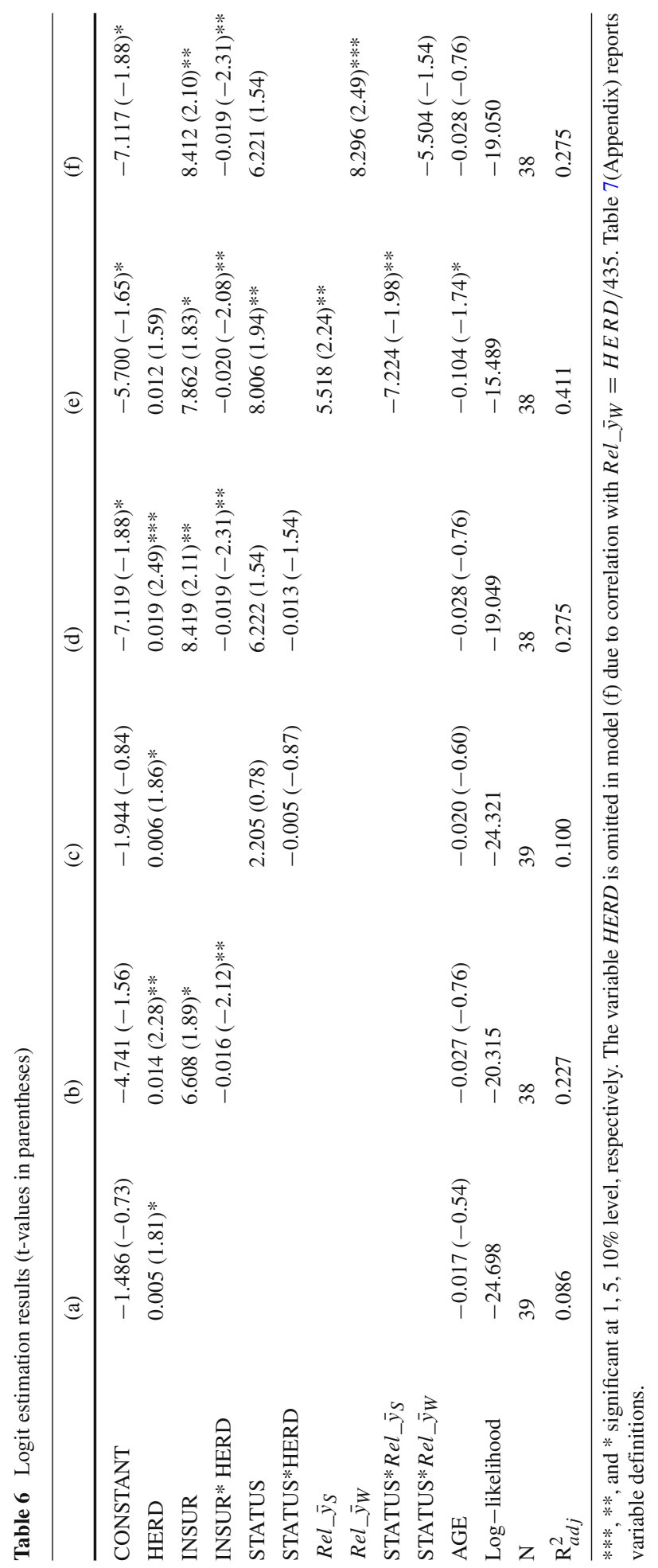


relative to other herders residing in the same summer district, model (e) introduces a variable $\mathrm{Rel}_{-} \bar{y}_{S}$ that measures individual herd size relative to average herd size in the respective summer district. Again, herd class averages are used as proxies for individual herd size. Hence, herders with, e.g., $\operatorname{Rel}_{-} \bar{y}_{S}=1.247$ keep $24.7 \%$ more animals than the average. On the other hand, herders with, e.g., Rel_ $\bar{y}_{S}=0.758$ keep $24.2 \%$ fewer animals than the average. A similar variable $R_{e} l_{-} \bar{y}_{W}$ is introduced in model (f) to capture any relative status motive compared with the average herd size on the common property winter pasture, that is, the western Finnmark average. The coefficient of $R e l_{-} \bar{y}_{S}$ is positive and significantly different from zero, which suggests that owners of herds above the summer district average are more likely to respond to a price increase by increasing the slaughter. Furthermore, the coefficient of STATUS is positive and significant. However, the interaction term STATUS*Rel_ $\bar{y}_{S}$ is negative and significantly different from zero. This suggests that owners keeping large herds relative to the summer district average, and who value the herd in terms of social status, are less likely to increase their slaughter than owners with no status motive. Note that the coefficient of $A G E$ turns out to be negative and weakly significantly different from zero in this model. The reason is that the oldest herders in the sample tend to keep herds above the summer district average, and when controlling for $R e l_{-} \bar{y}_{S}$ we see that these herders tend to be less likely to increase their slaughtering as the meat price increases. The coefficient of $\mathrm{Rel}_{-} \bar{y}_{W}$ (model (f)) is positive and significantly different from zero, reflecting that herders keeping large herds compared with the western Finnmark average are more likely to have a positive slaughter response. However, the interaction term $S T A T U S^{*} \operatorname{Rel}_{-} \bar{y}_{W}$ is negative but not significantly different from zero. Social status dependence on herd size relative to the average on the common property winter pasture, therefore, has no significant impact on the slaughter response.

\section{Concluding Remarks}

The theory of livestock as a buffer stock predicts that agropastoralists facing substantial risks, while at the same time restricted by weak credit and insurance markets, will use liquid assets such as livestock for self-insurance in order to smooth consumption. This paper examines this hypothesis for reindeer herding in northern Norway where the herders, in contrast to pastoralists in sub-Saharan Africa, face well-functioning credit markets and compensation schemes. This is done using survey data that include slaughter responses to a hypothetical increase in the meat price. The survey reveals to what extent the herders themselves see large reindeer herds as a source of insurance against adverse conditions, and we test whether this affects the slaughter response to a price increase. Furthermore, the data demonstrate that a rather large fraction of herders see herd size as important to gaining social status. Based on the theoretical model, it is hypothesized that preferences for such nonmarket values of the reindeer result in a weaker slaughter response. We are able to verify that preferences for reindeer as an insurance asset tend to reduce the slaughter response for owners of large herds. Furthermore, quite a large fraction of herders report prevailing preferences for social status, and we find evidence that such preferences reduce the slaughter response for herders keeping large herds relative to the summer district average.

The General Agreement between the reindeer herder organization and the Norwegian government includes a number of grants and subsidies, some of which directly enhance the reindeer slaughter price. Although the analysis presented here does not explicitly incorporate policy instruments, it nevertheless suggests that the slaughter response to subsidies aimed at increasing the producer price is more likely to be weaker for large herders with nonmarket 
motives than for herders with no such motives. Even though we cannot quantify the overall supply response based on this analysis, policy makers should be aware of possible perverse effects of slaughter subsidies. Recalling the problem of overgrazing in Finnmark evident over past decades, existing analyses have recommended making subsidies to some extent conditional on a slaughter requirement (see Riseth and Vatn 2009).

\section{Appendix}

\section{The Bioeconomic Model}

To derive condition (4), an expression for $V_{t+1}^{\prime}\left(y_{t+1}\right)$ is needed. Because the derivate of the value function is independent of time, we seek an expression for $V_{t}^{\prime}\left(y_{t}\right)$. When differentiating (3) with respect to $y_{t}$ and using the envelope theorem and Eq. (2) (cf. also the main text), we find $V_{t}^{\prime}\left(y_{t}\right)=W^{\prime}\left(y_{t} / \bar{y}_{t}\right) \frac{1}{\bar{y}_{t}}+\frac{1}{1+\delta} E_{t}\left[V_{t+1}^{\prime}\left(y_{t+1}\right)\left(1+F^{\prime}\left(y_{t}\right)\right) z_{t}\right]$. Inserting $\frac{1}{1+\delta} E_{t}\left\{V_{t+1}^{\prime}\left(y_{t}\right) z_{t}\right\}=U^{\prime}\left(\pi_{t}\right) P$ from the first order condition next yields $V_{t}^{\prime}\left(y_{t}\right)=$ $W^{\prime}\left(y_{t} / \bar{y}_{t}\right) \frac{1}{\bar{y}_{t}}+\left(1+f^{\prime}\left(y_{t}\right)\right) U^{\prime}\left(\pi_{t}\right) P$. When evaluating this expression at $(t+1)$ and inserting into the first order condition we end up with Eq. (4).

In the main text Sect. 4 empirical model, the individual herd size is specified as exogenous. Therefore, the following derives the relationship between slaughtering and meat price when the herd size is considered as exogenous. The utility of income function is specified as $U_{t}\left(\pi_{t}\right)=\left(P h_{t}\right)^{\alpha}$ with $0<\alpha<1$. We first look at the situation where no uncertainty is included. With this specification of the utility function and $z_{t}=1$, differentiation of the first order condition (4) with respect to $h_{t}$ and Pyields

$$
\begin{aligned}
& \left\{\begin{array}{l}
\left.\alpha(\alpha-1)\left(\pi_{t}\right)^{\alpha-2} P^{2}+[1 /(1+\delta)] W^{\prime \prime}\left(y_{t+1} / \bar{y}_{t+1}\right)\left(1 / \bar{y}_{t+1}\right)^{2}\right\} \\
+
\end{array}\right\} d h_{t} \\
& \quad=\left\{-\alpha^{2}\left(\pi_{t}\right)^{\alpha-1}+[1 /(1+\delta)]\left[1+F^{\prime}\left(y_{t+1}\right)\right] \alpha^{2}\left(\pi_{t+1}\right)^{\alpha-1}\right\} d P
\end{aligned}
$$

The bracket term on the left hand side is negative. When inserting from the first order condition, the bracket term on the right hand side equalizes $\left\{-\left[z_{t} /(1+\delta)\right]\right.$ $\left.W^{\prime}\left(y_{t+1} / \bar{y}_{t+1}\right)\left(1 / \bar{y}_{t+1}\right) / P\right\}<0$. The slaughter response $d h_{t} / d P$ is hence positive. This bracket term indicates that having a small future herd size relatively to the community average i.e., $y_{t+1} / \bar{y}_{t+1}$ is 'small', works in the direction of a stronger slaughter response, whereas keeping a relatively large herd tends to weaken the slaughter response.

Next, we look at the situation when uncertainty is included. Differentiation now yields

$$
\begin{aligned}
& \left\{\begin{array}{l}
P^{2} \alpha(\alpha-1)\left(\pi_{t}\right)^{\alpha-2}+[1 /(1+\delta)] E_{t}\left[W^{\prime \prime}\left(y_{t+1} / \bar{y}_{t+1}\right)\left(1 / \bar{y}_{t+1}{ }^{2}\right) z_{t}^{2}\right] \\
+[1 /(1+\delta)] E_{t}\left[F^{\prime \prime}\left(y_{t+1}\right) \alpha\left(\pi_{t+1}\right)^{\alpha-1} P z_{t}^{2}\right]
\end{array}\right\} d h_{t} \\
& = \\
& \left\{-\alpha^{2}\left(\pi_{t}\right)^{\alpha-1}+[1 /(1+\delta)] E_{t}\left[\left(1+F^{\prime}\left(y_{t+1}\right)\right) \alpha^{2}\left(\pi_{t+1}\right)^{\alpha-1} z_{t}\right]\right\} d P
\end{aligned}
$$

When inserting from the first order condition (4), the bracket term on the right hand side may also be written as $\left\{-E_{t}\left[W^{\prime}\left(y_{t+1} / \bar{y}_{t+1}\right)\left(1 / \bar{y}_{t+1}\right) z_{t}\right] \alpha / P\right\}$. Assume now that all herdsmen are equally affected by an environmental shock in the sense that the $y_{t+1} / \bar{y}_{t+1}$ remains unchanged. Then $E_{t}\left[W^{\prime}\left(y_{t+1} / \bar{y}_{t+1}\right)\left(1 / \bar{y}_{t+1}\right) z_{t}\right]=W^{\prime}\left(y_{t+1} / \bar{y}_{t+1}\right)$ $\left\{E_{t}\left[\left(1 / \bar{y}_{t+1}\right)\right] E_{t}\left[z_{t}\right]+\operatorname{cov}\left[1 / \bar{y}_{t+1}, z_{t}\right]\right\}$. The first bracket term $E_{t}\left[\left(1 / \bar{y}_{t+1}\right)\right] E_{t}\left[z_{t}\right]$ is 
positive and hence, works as in the deterministic model above in the direction of a positive slaughtering response. The covariance term is, however, negative and works in the opposite direction. This means that environmental uncertainty implies a smaller, or even a possible negative, slaughter response compared to the deterministic model.

The Data

Table 7 describes the data used in the regressions.

Table 7 Description of variables and descriptive statistics

\begin{tabular}{|c|c|c|c|c|c|}
\hline Variable & Description & $\mathrm{N}$ & Mean (SD) & Min & Max \\
\hline HERD & Herd size as class averages & 41 & $482.585(171.545)$ & 50 & 800 \\
\hline INSUR & $\begin{array}{l}=1 \text { if herdsman agree } \\
\text { or strongly agree } \\
\text { that the herd size is } \\
\text { important as } \\
\text { insurance, }=0 \\
\text { otherwise }\end{array}$ & 43 & $0.51(0.506)$ & 0 & 1 \\
\hline INSUR* HERD & Interaction term & 40 & $260.400(291.929)$ & 0 & 800 \\
\hline STATUS & $\begin{array}{l}=1 \text { if herdsman agree } \\
\text { or strongly agree } \\
\text { that the herd size is } \\
\text { important for social } \\
\text { status, }=0 \text { otherwise }\end{array}$ & 42 & $0.26(0.445)$ & 0 & 1 \\
\hline STATUS*HERD & Interaction term & 41 & 119.707 (236.595) & 0 & 800 \\
\hline $\operatorname{Rel}_{-} \bar{y}_{S}$ & $\begin{array}{l}\text { Deviation in herd size } \\
\text { from the summer } \\
\text { district average. } \\
\text { Summer district } \\
\text { average is set to } \\
\text { unity. }\end{array}$ & 41 & $1.172(0.523)$ & 0.108 & 3.150 \\
\hline $\operatorname{Rel}_{-} \bar{y}_{W}$ & $\begin{array}{l}\text { Deviation in herd size } \\
\text { from the winter } \\
\text { district average. } \\
\text { Winter district } \\
\text { average is set to } \\
\text { unity. }\end{array}$ & 41 & $1.112(0.399)$ & 0.115 & 1.939 \\
\hline STATUS*Rel_ $\bar{y}_{S}$ & Interaction term & 41 & $0.312(0.646)$ & 0 & 3.150 \\
\hline STATUS*Rel_ $\bar{y}_{W}$ & Interaction term & 41 & $0.278(0.551)$ & 0 & 1.939 \\
\hline AGE & Age of the respondent & 44 & $47.14(11.276)$ & 22 & 68 \\
\hline
\end{tabular}

Own survey (see main text Sect. 3)

Open Access This article is distributed under the terms of the Creative Commons Attribution Noncommercial License which permits any noncommercial use, distribution, and reproduction in any medium, provided the original author(s) and source are credited.

\section{References}

Austenå T, Sandvik G (1998) The legal status of rights to the resources of Finnmark with reference to previous regulations of the use of nonprivate resources. In: Berge Em, Stenseth NC (eds) Law and the governance of renewable resources-studies from northern Europe and Africa. ICS Press, California 
Austrheim G, Solberg E, Mysterud A, Daverdin M, Andersen R (2008) Cervid and livestock herbivory in Norwegian outlying land from 1949 to 1999. Report Serie 2008:2 NTNU-Vitenskapsmuseet Trondheim

Binswanger HP, McIntire J (1987) Behavioral and material determinants of production relations in landabundant tropical agriculture. Econ Dev Cult Change 36:73-99

Bostedt G (2005) Pastoralist economic behaviour: empirical results from reindeer herders in Northern Sweden. J Agric Resour Econ 30:381-396

Brekke KA, Howarth RB (2002) Status, growth and the environment: goods as symbols in applied welfare economics. Edward Elgar, Cheltenham

Chang C, Toutellotte PA (1993) Ethnoarchaeological survey of pastoral transhumance sites in the Grevena Region, Greece. J Field Archaeol 20:249-264

Clark CW (1990) Mathematical bioeconomics. Wiley Interscience, New York

Dasgupta P, Mäler K-G (1995) Poverty, institutions and the environmental resource-base. Handb Dev Econ 3:2371-2463

Doran HM, Low ARC, Kemp RL (1979) Cattle as a store of wealth in Swaziland. Am J Agric Econ 61:41-47

Fafchamps M (1998) The tragedy of the commons, livestock cycles and sustainability. J Afr Econ 7:384-423

Fafchamps M, Udry C, Czukas K (1998) Drought and saving in West-Africa: are livestock a buffer stock? J Dev Econ 55:273-305

Fraser I, Chisholm T (2000) Conservation or cultural heritage?, Cattle grazing in the Victoria Alpine National Park. Ecol Econ 33:63-75

Jarvis LS (1974) Cattle as capital goods and ranchers as portfolio managers: an application to the Argentine cattle sector. J Polit Econ 82:489-520

Johannesen AB, Skonhoft A (2009) Local common property exploitation with rewards, Land Economics. Land Econ 85:637-654

Johansen B, Karlsen SR (2005) Monitoring vegetation changes on Finnmarksvidda, Northern Norway, using Landsat MSS and Landsat TM/ETM+ satellite images. Phytocoenologia 35:969-984

Johnston J, Dinardo J (1997) Econometric methods. McGraw Hill, Singapore

Labba N, Granefjell S-O, Linder B, Riseth JÅ (2006) Analyse av den samiske reindriftens $\varnothing$ konomiske tilpasning (in Norwegian). Nordisk Samisk Institutt, Kautokeino

McPeak J (2004) Contrasting income shocks with asset shocks: livestock sales in northern Kenya. Oxford Econ Pap 56:263-284

Norwegian Reindeer Husbandry Administration (NRHA) (2007) Ressursregnskap for reindriftsnæringen (in Norwegian), Alta

Perrings C (1994) Stress, shock, and sustainability of resource use in semi-arid environments. Ann Reg Sci 28:31-53

Perrings C, Walker BW (1995) Biodiversity loss and the economics of discontinuous change in semiarid rangelands. In: Perrings C, Mäler K-G, Folke C, Holling CS, Jansson B-O (eds) Biodiversity loss. Cambridge University Press, Cambridge

Reed WJ (1979) Optimal escapement levels with stochastic and deterministic harvesting models. J Environ Econ Manage 6:350-363

Riseth JÅ, Vatn A (2009) Modernization and pasture degradation: a comparative study of two Sámi reindeer pasture regions in Norway. Land Econ 85:87-106

Rosen S (1987) Dynamic animal economics. Am J Agric Econ 69:547-557

Skonhoft A (1999) Exploitation of an unmanaged local common. On the proplems of overgrazing, regulation and distribution. Nat Resour Model 12:461-479

Skonhoft A, Johannesen AB (2000) On the problem of overgrazing (in Norwegian). Norsk Økonomisk Tidsskrift 2:65-86

St. prp. nr. 1 (2007-2008), white paper Department of agriculture and food (in Norwegian) kapittel 1151 Til Gjennomføring, Landbruks- og matdepartementet, Oslo

St. prp. nr. 76 (2008-2009), white paper Department of agriculture and food (in Norwegian) Om reindriftsavtalen 2009/2010, Landbruks- og matdepartementet, Oslo

Walker B (1993) Rangeland ecology: understanding and managing change. Ambio 22:80-87 